\title{
Bacoside A Induced Sub-G0 Arrest and Early Apoptosis in Human Glioblastoma Cell Line U-87 MG through Notch Signaling Pathway
}

\author{
Madhuri G S Aithal, Narayanappa Rajeswari \\ Department of Biotechnology, Dayananda Sagar College of Engineering, Bangalore, India
}

Received April 21, 2018

Revised October 20, 2018

Accepted December 10, 2018

\section{Correspondence}

Narayanappa Rajeswari Department of Biotechnology,

Dayananda Sagar

College of Engineering,

Affiliated to Visvesvaraya

Technological University,

Kumaraswamy Layout,

Bangalore-560078, Karnataka, India

Tel: $+91-9480648300$

Fax: $+91-26660789$

E-mail: nraja7@gmail.com
Background Glioblastoma multiforme (GBM) is a highly malignant brain tumor with a worst prognosis of less than one year despite advance treatment facilities. Among various signaling pathway genes displaying genetic modifications, aberrant expression of Notch pathway genes is frequent in GBM offering novel therapeutic targets. Herbal extracts having anticancer properties are used in adjuvant therapy that is safe and affordable as compared to chemotherapeutics. Bacopa monnieri has been used for the development of brain cells because of its neuroprotective properties. Its anticancer properties have shown to be promising in cancer treatment.

Methods The anticancer properties of Bacoside A, an active and abundant component of Bacopa monnieri was assessed on U-87 MG cell line and its effects on expression of Notch pathway genes were studied. Cell cycle arrest and apoptosis were studied using flow cytometry. Expression of Notch pathway genes comprising of Notch receptors (notch1, notch2, notch3 and notch4), ligands (jagged1 and jagged2), a component of gamma-secretase complex (APH1A) and downstream target (HES1) were evaluated by quantitative real-time PCR.

Results Bacoside A exhibited considerable cytotoxicity on U-87 MG cells inducing cell cycle arrest and apoptosis. Cell cycle analysis revealed a significant arrest of $39.21 \%$ cells in sub-G0 phase at $80 \mu \mathrm{g} / \mathrm{mL}$ concentration, increasing to $53.21 \%$ at a higher concentration of $100 \mu \mathrm{g} / \mathrm{mL}$. The fraction of early apoptotic cells in control was low (3.48\%) that increased substantially to $31.36 \%$ and $41.11 \%$ after $80 \mu \mathrm{g} / \mathrm{mL}$ and $100 \mu \mathrm{g} / \mathrm{mL}$ of Bacoside A treatment respectively. Additionally, the expression of notch1 gene decreased after exposure to Bacoside A with a fold change of 0.05 , whereas HES1 gene expression was increased by 25 fold.

Conclusion These data indicate that Bacoside A has a possible anticancer activity that could be inducing cell cycle arrest and apoptosis through Notch pathway in GBM in vitro.

Key Words Glioblastoma; Notch; Bacoside A; Cell cycle; Apoptosis; Gene expression.

\section{INTRODUCTION}

Glioblastoma multiforme (GBM), a grade IV glioma, is the most common and most aggressive primary brain tumor [1]. Additionally, GBM is highly malignant having poor prognosis, with a median survival of 12 to 15 months [2]. The standard

This is an Open Access article distributed under the terms of the Creative Commons Attribution Non-Commercial License (https://creativecommons.org/licenses/by-nc/4.0) which permits unrestricted non-commercial use, distribution, and reproduction in any medium, provided the original work is properly cited.

Copyright $\odot 2019$ The Korean Brain Tumor Society, The Korean Society for NeuroOncology, and The Korean Society for Pediatric Neuro-Oncology therapy for GBM is surgery followed by radiation and chemotherapy. The effect of currently used chemotherapeutic drug Temozolomide is not satisfactory since there is no significant improvement in patient survival. Furthermore, a number of genetic alterations including several cell signaling pathway genes are involved in GBM pathogenesis. One such alteration that occurs frequently in GBM is aberrant expression of Notch signaling pathway genes. The Notch signaling pathway plays a critical role in maintenance and self-renewal of neural stem cells [3]. Since Notch pathway is involved in maintaining cells in an undifferentiated state, dysregulated Notch genes have 
been associated with a growing list of cancers including T-cell acute lymphoblastic leukemia, Hodgkin lymphoma, multiple myeloma, glioma, cervical, pancreatic, lung, breast cancer, hepatocellular carcinoma, etc. [4,5]. In an attempt to better understand GBM, several studies have examined genetic alterations in Notch signaling pathway [6-8]. Also, Notch inhibition has been shown to result in decreased proliferation and selfrenewal of GBM cells in several instances [9-11]. Notch signaling pathway has thus proved to be a novel therapeutic target in the treatment of GBM.

Numerous studies have documented various herbal products as novel anticancer drugs for efficient cancer treatment. Currently used chemotherapeutic agents are systemic and cause harmful side effects. Compared to highly toxic and expensive chemotherapeutic agents, herbal products have enabled the development of safer, nontoxic and affordable treatment for cancer. Bacoside A is the most studied constituent of Bacopa monnieri, locally known as Brahmi. Brahmi has been used for centuries in Ayurveda as a rejuvenating herb for nerve and brain cells development because of its neuroprotective properties. Bacopa monnieri has been found to have antioxidant properties which is used to treat oxidative stress caused due to aging and cigarette smoke [12,13]. It is observed to inhibit intraneuronal lipofuscin accumulation and necrotic alteration caused due to neurotoxicity in the hippocampus [14]. Its ability to cross the blood brain barrier has been exploited in the treatment of Alzheimer's and Parkinson's disease, attention deficit disorder, etc. Additionally, Bacopa monnieri as a crude plant extract or as individual constituents have been used in the treatment of cancer. However, the antitumor property of Brahmi has not been studied extensively in recent times. Various in vitro and in vivo studies have shown cytotoxic and antiproliferative properties of Bacopa monnieri whole plant extract $[15,16]$. Furthermore, research have suggested that the anticancer effect of Bacopa monnieri extracts is possibly due to inhibition of DNA replication, DNA fragmentation and activation of apoptotic pathway $[17,18]$. Collectively, these data suggest that Brahmi emerges as a promising therapy and further research needs to be done to check the antitumor property of the herb in treating GBM.

In the present study, we explored the antitumor properties of a bioactive phytochemical Bacoside A in human GBM cell line U-87 MG and its effects on the expression of Notch signaling pathway genes. This could enhance our understanding of the role of Notch genes in GBM and present a specific molecular target for developing a much needed herbal therapy to treat GBM.

\section{MATERIALS AND METHODS}

\section{Cell culture}

Human Glioblastoma cell line U-87 MG (ATCC, Manassas, VA, USA) was cultured in DMEM (Sigma Aldrich, St. Louis, MO, USA) supplemented with 10\% FBS (Invitrogen, Camarillo, CA, USA). The cells were cultured in T25 flasks and grown in a humidified $5 \% \mathrm{CO}_{2}$ incubator at $37^{\circ} \mathrm{C}$. The cells were trypsinized and sub cultured on reaching $70-80 \%$ confluence. Bacoside A (Natural Remedies, Bangalore, India) was dissolved in HPLC grade methanol (Fisher Scientific, Waltham, MA, USA) to obtain a stock solution of $3.2 \mathrm{mg} / \mathrm{mL}$ concentration by making up the volume with DMEM. After preliminary dose response studies (data not shown), working solutions were prepared from the stock at concentrations of $320,160,80,40,20,10$, and $5 \mu \mathrm{g} / \mathrm{mL}$ with DMEM.

\section{MTT assay}

The cells were seeded in a 96-well plate with 50,000 cells per well in medium and incubated for $24 \mathrm{~h}$ at $37^{\circ} \mathrm{C}, 5 \% \mathrm{CO}_{2}$ and $95 \%$ air atmosphere. After $24 \mathrm{~h}$ incubation, cells were treated with different concentrations of Bacoside A $(320,160$, $80,40,20,10$ and $5 \mu \mathrm{g} / \mathrm{mL}$ ), each in triplicate for another $24 \mathrm{~h}$. The cells were then harvested and washed with $1 \times$ PBS (HiMedia, Mumbai, India). $100 \mu \mathrm{L}$ of MTT $(0.5 \mathrm{mg} / \mathrm{mL}$ ) (Sigma Aldrich) was added to each well and incubated for $3.5 \mathrm{~h}$ at $37^{\circ} \mathrm{C}$ before $100 \mu \mathrm{L}$ of $100 \%$ DMSO (HiMedia) was added. The absorbance was measured on a microplate reader (Tecan, Männedorf, Switzerland) at a wavelength of $490 \mathrm{~nm}$. The solvent methanol treated cells served as control. The final concentration of methanol in culture medium did not exceed $1 \%$ and was proved not to affect the experiment. Percentage inhibition was expressed using the following formula:

$\%$ Inhibition

$=[1-(\mathrm{OD}$ of treated cells $/ \mathrm{OD}$ of control cells $)] \times 100$.

$\mathrm{IC}_{50}$ value was determined by plotting $\%$ inhibition on $y$-axis against concentration of Bacoside $\mathrm{A}$ on $\mathrm{X}$-axis which gives the concentration of drug required for $50 \%$ inhibition. $\mathrm{IC}_{50}$ values were derived from a non-linear regression model (curvefit), computed using GraphPad Prism (La Jolla, CA, USA).

\section{Cell cycle analysis}

Cell cycle analysis was performed by flow cytometry using propidium iodide (PI) based measurements of the DNA content in the cells. Briefly, U-87 MG cells were treated with 80 $\mu \mathrm{g} / \mathrm{mL}$ and $100 \mu \mathrm{g} / \mathrm{mL}$ Bacoside A for $24 \mathrm{~h}$. Treated and untreated cells were harvested and washed twice with $1 \times$ PBS $\left(4,000 \mathrm{rpm}, 10 \mathrm{~min}, 25^{\circ} \mathrm{C}\right)$. Thereafter, cells were fixed with $70 \%$ ice cold ethanol and stored at $4^{\circ} \mathrm{C}$ overnight. The cells were then washed twice with $1 \times$ PBS $(4,000 \mathrm{rpm}, 10 \mathrm{~min}$, 
$\left.25^{\circ} \mathrm{C}\right)$. Later, cells were stained with $500 \mu \mathrm{L}$ of PI $(0.05 \mathrm{mg} / \mathrm{mL}$ in PBS containing $0.05 \mathrm{mg} / \mathrm{mL}$ RNase A) for $15 \mathrm{~min}$ at room temperature in dark. Cells were analyzed for DNA content on a FACSCalibur ${ }^{\mathrm{TM}}$ flow cytometer using Cell Quest acquisition and analysis software (Becton Dickinson, Heidelberg, Germany).

\section{Apoptosis assay}

U-87 MG cells were incubated with $80 \mu \mathrm{g} / \mathrm{mL}$ and $100 \mu \mathrm{g} /$ $\mathrm{mL}$ Bacoside A for $24 \mathrm{~h}$ before the cells were harvested. The treated and untreated cells were washed twice in $1 \times$ PBS $\left(4,000 \mathrm{rpm}, 10 \mathrm{~min}, 25^{\circ} \mathrm{C}\right)$, and the cell pellet obtained was resuspended in Annexin V binding buffer at room temperature to a concentration of $1 \times 10^{6}$ cells $/ \mathrm{mL}$. To the resuspended solution, $5 \mu \mathrm{L}$ of Annexin V-FITC and $5 \mu \mathrm{L}$ of PI were added. The resulting mixtures were gently mixed and incubated for $15 \mathrm{~min}$ at room temperature in dark. An additional $400 \mu \mathrm{L}$ of binding buffer was added to each tube and flow cytometric evaluation was conducted immediately on a FACSCalibur ${ }^{\mathrm{TM}}$ flow cytometer using Cell Quest acquisition and analysis software (Becton Dickinson).

\section{Fluorescence microscopy}

The Annexin V-FITC/PI staining procedure of the treated and untreated cells was performed as above. After staining, 20 $\mu \mathrm{L}$ of sample was mounted onto a glass slide with a cover slip and observed under $40 \times$ objective lens of fluorescence microscope (Lawrence \& Mayo, Mumbai, India). Images of cells were obtained with a digital camera (DSC-W830, Sony, Tokyo, Japan) connected to the microscope.

\section{DNA fragmentation analysis}

U-87 MG cells were cultured for $24 \mathrm{~h}$ before treating with $80 \mu \mathrm{g} / \mathrm{mL}$ and $100 \mu \mathrm{g} / \mathrm{mL}$ of Bacoside $\mathrm{A}$ and grown at $37^{\circ} \mathrm{C}$ in a humidified $5 \% \mathrm{CO}_{2}$ incubator for $24 \mathrm{~h}$. At the end of treatment, both floating cells and adherent cells were harvested. Genomic DNA was isolated from treated and untreated cells by TRIzol (Invitrogen) method as recommended by the manufacturer. DNA samples were mixed with loading dye (Bangalore GeNei, Bangalore, India) and resolved in 1\% agarose gel (Lonza, Basel, Switzerland) containing $0.5 \mu \mathrm{g} / \mathrm{mL}$ ethidium bromide (Sigma Aldrich). Electrophoresis was carried out at $75 \mathrm{~V}$ for 60 min using $1 \times$ TAE buffer $(0.04 \mathrm{M}$ Tris acetate, 0.001 M EDTA, pH 8.2). After electrophoresis, DNA in the gel was visualized and photographed in a gel documentation system (UVItec, Cambridge, UK).

\section{RNA isolation and reverse transcription}

U-87 MG cells were treated with $80 \mu \mathrm{g} / \mathrm{mL}$ of Bacoside A corresponding to their $\mathrm{IC}_{50}$ value for $24 \mathrm{~h}$. Treated and untreat- ed cells were harvested and total RNA was extracted by TRIzol (Invitrogen) method as recommended by the manufacturer. RNA samples extracted were quantified using NanoDrop 1,000 spectrophotometer (Thermo Scientific, DE, USA). $1 \mu \mathrm{g}$ of RNA was reverse transcribed to cDNA using high-capacity cDNA reverse transcription kit (Applied Biosystems, CA, USA) as per manufacturer's protocol.

\section{Quantitative real-time PCR}

The relative quantitation of expression levels of eight Notch pathway genes (notch1, notch2, notch3, notch4, jagged1, jagged2, APH1A and HES1) was carried out on Applied Biosystems StepOnePlus ${ }^{\mathrm{TM}}$ Instrument (CA, USA). Amplification was performed using SYBR Green master mix (Fermentas, MA, USA), $150 \mathrm{nM}$ forward and reverse primer (Sigma Aldrich) and 20 ng of cDNA template. Amplification was carried out with an initial denaturation step at $95^{\circ} \mathrm{C}$ for $10 \mathrm{~min}$ followed by 45 cycles at $95^{\circ} \mathrm{C}$ for $15 \mathrm{~s}, 57^{\circ} \mathrm{C}$ for $30 \mathrm{~s}$ and $72^{\circ} \mathrm{C}$ for $30 \mathrm{~s}$ in a total of $12.5 \mu \mathrm{L}$ reaction volume. All reactions were run in triplicates and the mean was used for further calculations. TATA binding protein (TBP), a housekeeping gene was chosen as an appropriate internal control after validating four conventionally used housekeeping genes (GAPDH, TBP, B2M and RPL13A) in gene expression studies (data not shown). Untreated cells were used as calibrator. Relative quantification was done by $2^{-\Delta \Delta C t}$ method, the data are presented as fold change in gene expression normalized to an endogenous reference gene and relative to the calibrator, and is given by:

$$
\text { Amount of target }=2^{-\Delta \Delta C t} \text {, }
$$

where $\Delta \Delta \mathrm{Ct}=\left(\mathrm{Ct}_{\text {Target }}-\mathrm{Ct}_{\mathrm{TBP}}\right)_{\text {Treated }}-\left(\mathrm{Ct}_{\text {Target }}-\mathrm{Ct}_{\mathrm{TBP}}\right)_{\text {Untreated. }}$

Statistical significance was assessed by calculating probability values through Student's $t$ test using GraphPad. $p$ values less than 0.05 were considered as significant.

\section{RESULTS}

\section{Cytotoxicity}

Cytotoxic effect of Bacoside A was evaluated on U-87 MG cells using the MTT colorimetric assay. Results indicated that Bacoside A possessed dose-dependent cytotoxic effects against human GBM cells (Fig. 1, Table 1). It is evident from the results in the Table 1 that the cell viability was not significantly affected at concentrations up to $20 \mu \mathrm{g} / \mathrm{mL}$ of Bacoside A, which retained $80.88 \%$ of viable cells. However, $74.21 \%$ inhibition was observed at concentration $320 \mu \mathrm{g} / \mathrm{mL}$. Thus, to exclude the cytotoxicity of excess Bacoside $\mathrm{A}, \mathrm{IC}_{50}$ value was determined and found to be $83.01 \mu \mathrm{g} / \mathrm{mL}$ against U-87 MG cell line. 


\section{Cell cycle arrest}

In order to evaluate the effects of Bacoside A on cell cycle, U-87 MG cells were treated with the drug at $80 \mu \mathrm{g} / \mathrm{mL}$ and $100 \mu \mathrm{g} / \mathrm{mL}$ concentration for $24 \mathrm{~h}$. DNA content in sub-G0 phase, G0/G1 phase, S phase, and G2/M phase were determined at the end of the treatment by flow cytometry. Fig. 2 and 3 shows the effects of Bacoside A on sub-G0 phase, G0/ G1 phase, S phase and G2/M phase in U-87 MG cells after 24 $\mathrm{h}$ treatment. Untreated cells showed a normal cell cycle with hardly any sub-G0 DNA (Fig. 2A, Fig. 3). Treatment with Bacoside A caused a significant increase in sub-G0 phase, indicative of apoptosis. This increase in sub-G0 cell population was accompanied with a decrease in the population of cells in G0/ $\mathrm{G} 1, \mathrm{~S}$ and $\mathrm{G} 2 / \mathrm{M}$ phase. The treatment at $80 \mu \mathrm{g} / \mathrm{mL}$ concen-

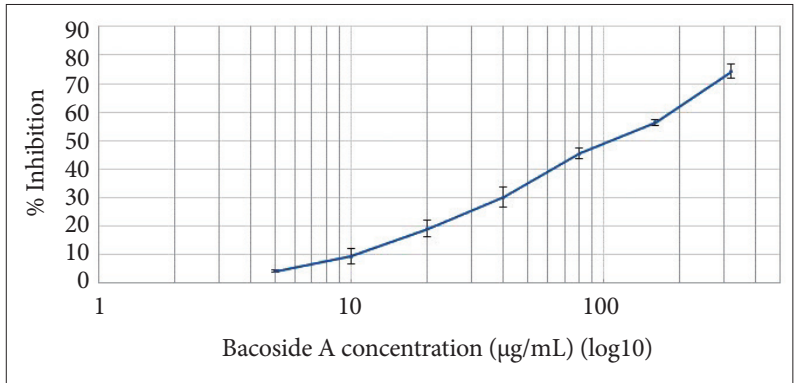

Fig. 1. Effect of Bacoside A on human glioblastoma multiforme cell line U-87 MG as determined by MTT assay. tration caused an arrest of $39.21 \%$ cells in sub-G0 phase, further increasing to $53.21 \%$ at the higher concentration of 100 $\mu \mathrm{g} / \mathrm{mL}$ compared to untreated cells $(0.37 \%)(p=0.022)$ (Fig. $2 \mathrm{~B}$ and C, Fig. 3). Thus, these results revealed that an increase of Bacoside A concentration led to increased apoptosis in human GBM cell line.

\section{Apoptosis}

By staining Bacoside A treated U-87 MG cells with Annexin V-FITC and PI, flow cytometry was carried out to deter-

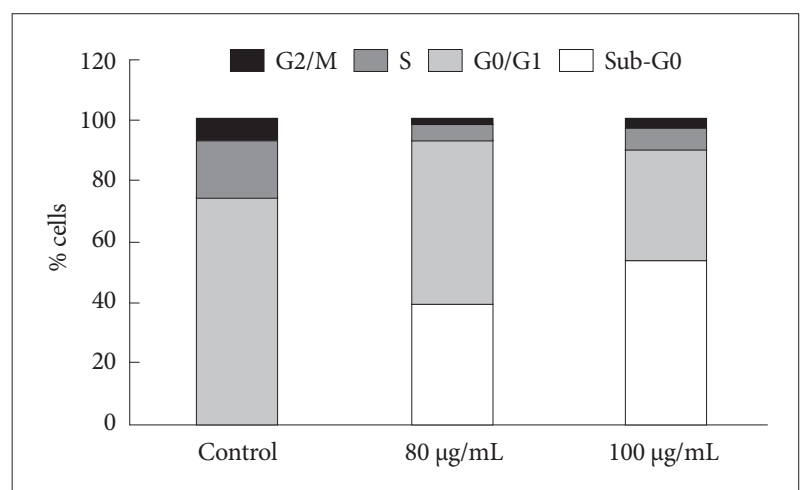

Fig. 3. Bar graph obtained from cell cycle analysis of control, 80 $\mu \mathrm{g} / \mathrm{mL}$ and $100 \mu \mathrm{g} / \mathrm{mL}$ of Bacoside A respectively showing the percentage of cells in different phases of cell cycle (G2/M, S, G0/ G1 and Sub-G0).

Table 1. Cytotoxicity of bacoside A on human glioblastoma multiforme cell line U-87 MG as determined by MTT assay

\begin{tabular}{cccccc}
\hline No & Concentration $(\mu \mathrm{g} / \mathrm{mL})$ & Absorbance at $490 \mathrm{~nm}$ & \% Cell inhibition & \% Cell viability & $\mathrm{IC}(\mu \mathrm{g} / \mathrm{mL})$ \\
\hline 1 & 320 & 0.1753 & 74.21 & 25.79 \\
2 & 160 & 0.2957 & 56.50 & 43.50 \\
3 & 80 & 0.3703 & 45.53 & 54.47 \\
4 & 40 & 0.4758 & 30.01 & 69.99 & 80.88 \\
5 & 20 & 0.5498 & 19.12 & 90.57 \\
6 & 10 & 0.6157 & 9.43 & 95.84 \\
7 & 5 & 0.6515 & 4.16 & 100.00 \\
\hline
\end{tabular}

Values are the mean of triplicates.
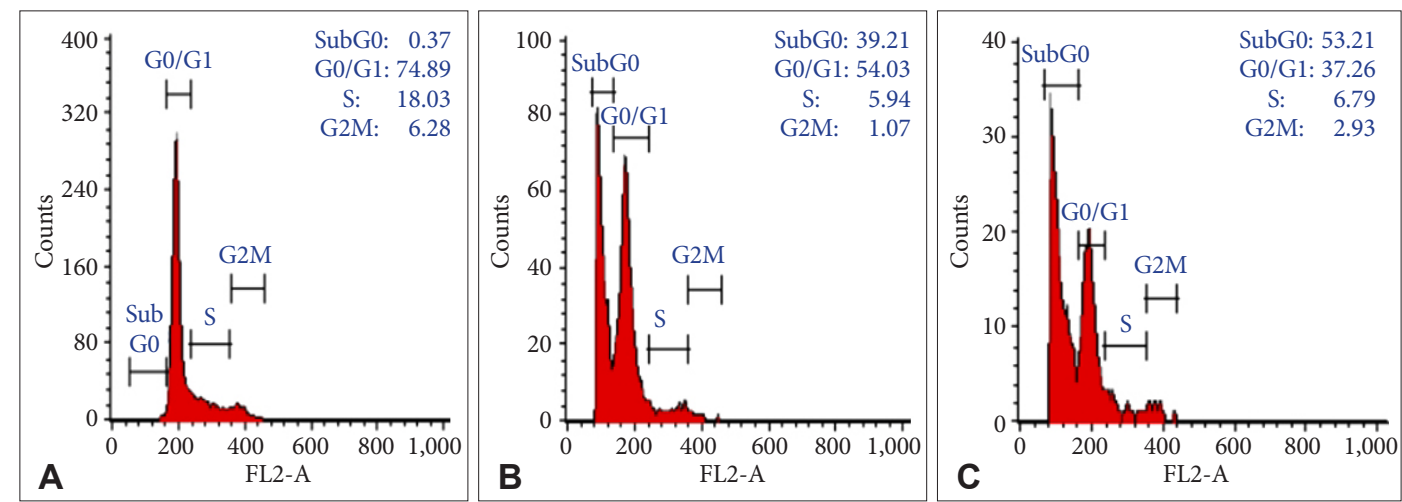

Fig. 2. Cell cycle profiles of untreated (A) and treated U-87 MG cells with $80 \mu \mathrm{g} / \mathrm{mL}$ (B) and $100 \mu \mathrm{g} / \mathrm{mL}$ (C) of Bacoside A respectively for 24 $\mathrm{h}$ as determined by flow cytometry. 
mine the percentage of apoptotic and necrotic cells after $24 \mathrm{~h}$ treatment. The percentage of viable U-87 MG cells (AnV-/ PI-) after $80 \mu \mathrm{g} / \mathrm{mL}$ and $100 \mu \mathrm{g} / \mathrm{mL}$ of Bacoside A treatment decreased to $67.77 \%$ and $58.56 \%$ respectively when compared with the untreated control (93.87\%) $(p=0.021)$. Furthermore, the percentage of early apoptotic cells (AnV+/PI-) increased from $3.48 \%$ in untreated control cells to $31.36 \%$ and $41.11 \%$ in $80 \mu \mathrm{g} / \mathrm{mL}$ and $100 \mu \mathrm{g} / \mathrm{mL}$ of Bacoside A treated cells respectively ( $p=0.021$ ) (Fig. 4). Thus, Bacoside A induces early apoptosis in human GBM cell line in a dose dependent manner.

\section{Fluorescence microscopy}

U-87 MG cells treated with Bacoside A were stained with Annexin V-FITC/PI and observed under a fluorescence microscope. Bacoside A treated cells when stained with PI displayed red fluorescence due to fragmented chromatin and green fluorescence on the cell membrane when stained with Annexin V-FITC. Different labelling patterns enabled identification of different cell populations. Early apoptotic cells showed affinity towards Annexin V-FITC alone and were devoid of PI (Fig. 5A). Late apoptotic/necrotic cells showed affinity for both Annexin V-FITC and PI displaying red nucle- us and a halo of green on the cell surface (Fig. 5B). Dead cells showed affinity towards PI alone indicating completely degraded cell membrane (Fig. 5C).

\section{DNA fragmentation}

DNA from Bacoside A treated U-87 MG cells showed DNA ladder formation (Fig. 6) which is a hallmark property of apoptosis further confirming the induction of cell death by the drug. However, DNA from the control cells was not degraded. Together, these results could indicate that Bacoside A induces apoptosis in human GBM cells in vitro.

\section{Gene expression}

To examine if Bacoside A induced cell death via Notch signaling pathway, we studied expression of eight Notch pathway genes by real-time PCR to determine whether Notch pathway genes were modulated by Bacoside A. Bacoside A did not affect the expression levels of notch2, notch3, notch4, JAG1, $J A G 2$ and $A P H 1 A$ genes as compared to the untreated control cells (Fig. 7). However, the expression of Notch receptor notch1 was decreased significantly with a fold change of $0.05(p=$ 0.005) and the expression of Notch downstream target HES1
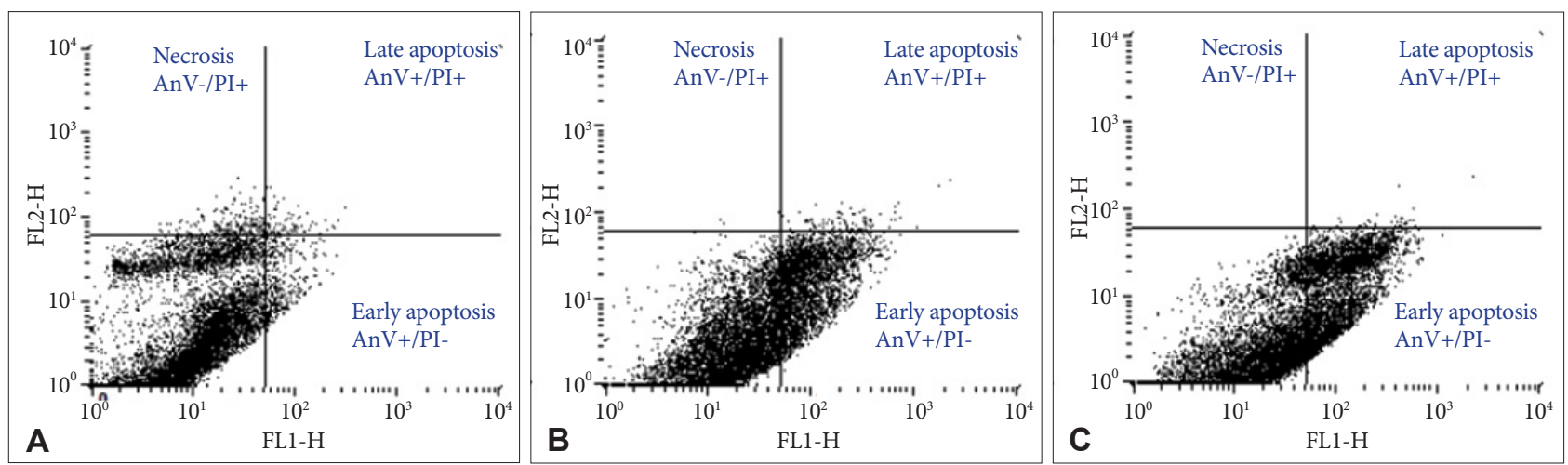

Fig. 4. Apoptosis in untreated (A) and treated U-87 MG cells with $80 \mu \mathrm{g} / \mathrm{mL}(\mathrm{B})$ and $100 \mu \mathrm{g} / \mathrm{mL}(\mathrm{C})$ of Bacoside A respectively for $24 \mathrm{~h}$ as determined by flow cytometry.
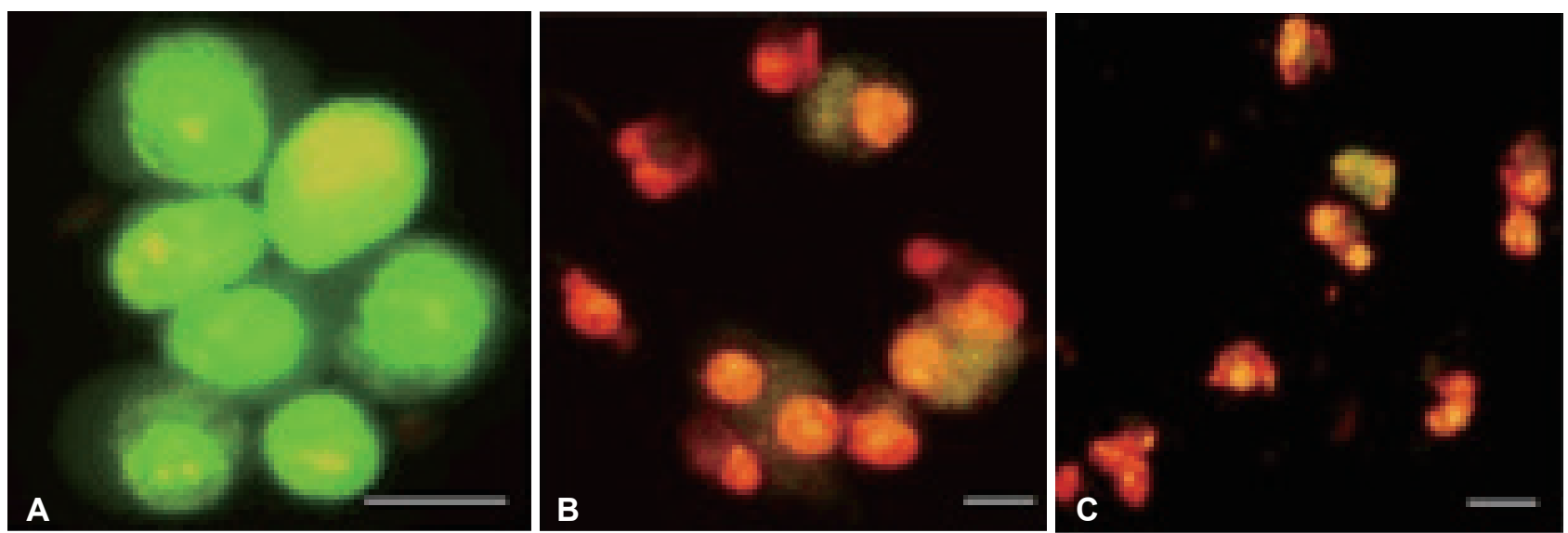

Fig. 5. U-87 MG cells treated with Bacoside A stained with Annexin V-FITC/PI displaying early apoptotic cells (A), late apoptotic/necrotic cells (B) and dead cells (C) as observed under a fluorescent microscope. Scale bar, $50 \mu \mathrm{m}$. 


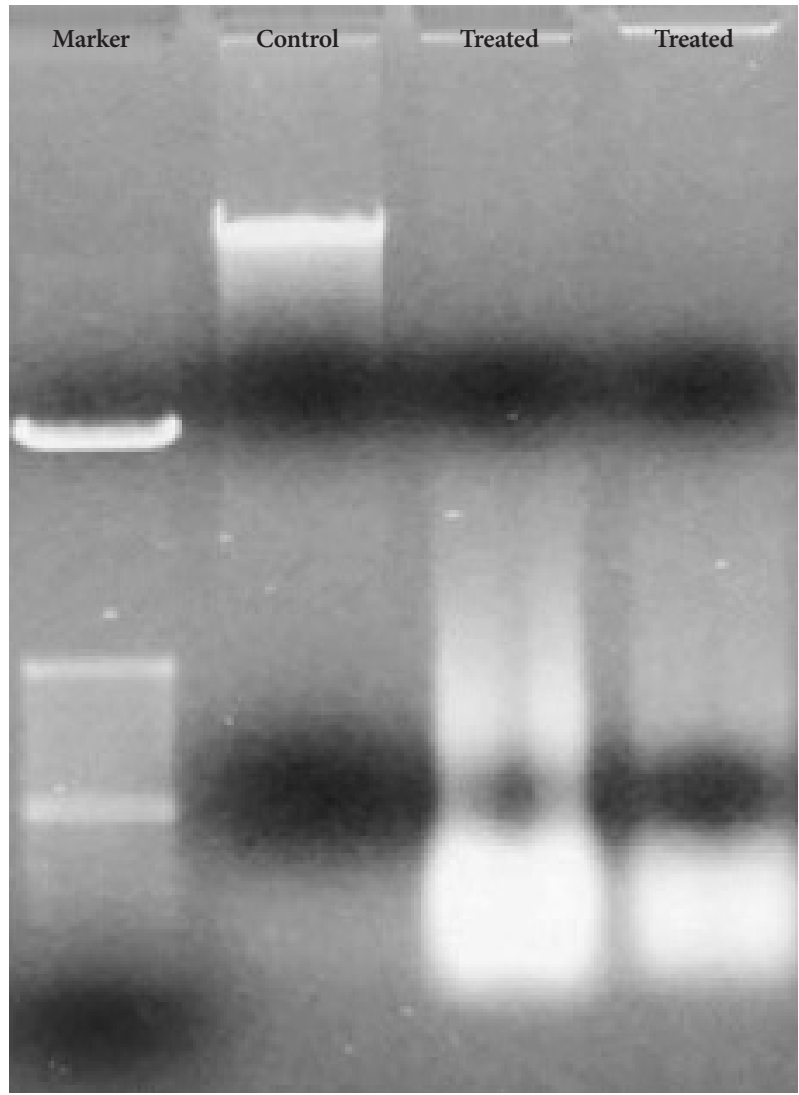

Fig. 6. Bacoside A induced DNA fragmentation in U-87 MG cells analysed by agarose gel electrophoresis.

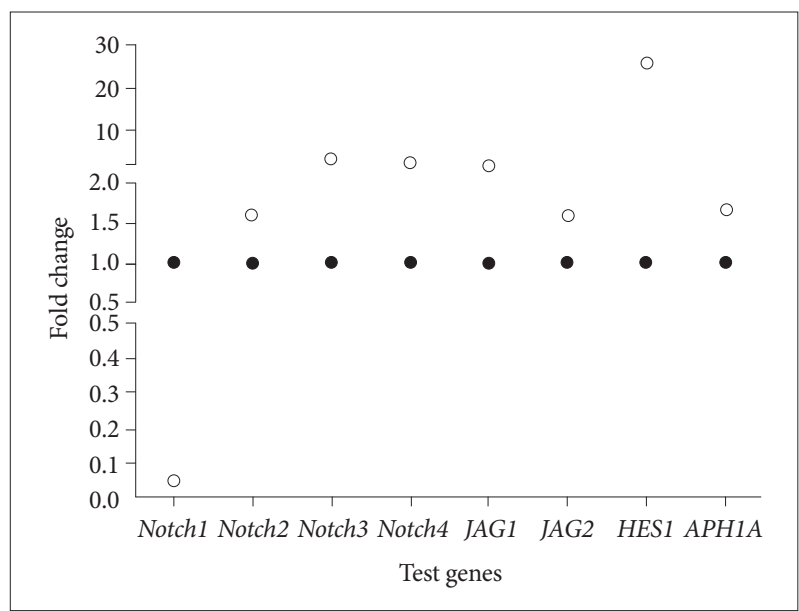

Fig. 7. Scatter plots of differentially expressed Notch pathway genes in Bacoside A treated U-87 MG cells (open circles) compared to untreated cells (filled circles) at $24 \mathrm{~h}$ incubation in terms of fold change derived from real-time PCR analysis.

was increased by 25 fold after $80 \mu \mathrm{g} / \mathrm{mL}$ of Bacoside A treatment for $24 \mathrm{~h}$ ( $p=0.017$ ) (Table 2, Fig. 7). These results provide added data for Bacoside A induced apoptosis via the Notch signaling pathway in U-87 MG cells.
Table 2. Expression of Notch genes in U-87 MG cells after treatment with $80 \mu \mathrm{g} / \mathrm{mL}$ of Bacoside $A$ at $24 \mathrm{~h}$ incubation in terms of fold change

\begin{tabular}{lcc}
\hline Genes & Status & Fold change \\
\hline Notch1 & $\downarrow$ & 0.05 \\
Notch2 & $\leftrightarrow$ & 1.61 \\
Notch3 & $\uparrow$ & 3.53 \\
Notch4 & $\uparrow$ & 2.60 \\
$J A G 1$ & $\uparrow$ & 2.08 \\
$J A G 2$ & $\leftrightarrow$ & 1.60 \\
HES1 & $\uparrow$ & 25.81 \\
APH1A & $\leftrightarrow$ & 1.67 \\
\hline
\end{tabular}

Values were derived from qPCR. $\uparrow$, upregulated with respect to untreated sample $(>2)$; $\downarrow$, downregulated with respect to untreated sample $(<0.5) ; \leftrightarrow$, no significant change with respect to untreated sample $(0.5-2)$

\section{DISCUSSION}

GBM is a complex disease which is extremely refractory to therapy, in part because of poor understanding of several genetic alterations involved in its pathogenesis. Most of the patients who succumb to GBM within one year despite advance treatment highlight the need for better therapies acting at the genetic level. In recent years, herbal therapy has gradually emerged as a novel cancer treatment having a huge advantage over conventional chemotherapeutics. The common features of inducing cell cycle arrest and apoptosis by chemotherapic agents in cancer cells are the focus of this study. We investigated the anticancer property of Bacoside $\mathrm{A}$ which is the most studied component of Bacopa monnieri, against human GBM cell line U-87 MG. Untreated cells were used as experimental control in this study. Bacoside A has gained significant attention in recent years as a lead for the development of anticancer therapeutics [19-21]. It is a blend of bacoside A3, bacopacide II, bacopasaponin C, and a jujubogenin isomer of bacosaponin C [22]. It is however found to be safe and nontoxic on normal cells making it a suitable therapeutic lead [23-25]. The aim of this work was to determine the effects of Bacoside A on cell cycle arrest and apoptosis with associated impact on expression of Notch pathway genes in human GBM cell line U-87 MG.

Evaluation of cytotoxicity revealed that Bacoside A showed dose-dependent cytotoxicity against U-87 MG cells. The $\mathrm{IC}_{50}$ value was found to be less than $100 \mu \mathrm{g} / \mathrm{mL}$ signifying potent cytotoxic effects in GBM cells. We investigated the cell cycle specific effects of Bacoside A against human GBM cells by PI based cell cycle analysis using flow cytometry. Cancer cell cycle specific drugs cause cell death by blocking cell cycle at specific cell cycle checkpoints (sub-G0, G0/G1 phase, S phase and G2/M phase) [26]. These drugs could induce apoptosis 
(sub-G0 arrest) or inhibit cell proliferation (G0/G1 phase arrest), or DNA replication (S phase arrest) or mitosis (G2/M phase arrest) [27]. The flow cytometry result showed an arrest of $39.21 \%$ cells in sub-G0 phase at $80 \mu \mathrm{g} / \mathrm{mL}$ concentration, further increasing to $53.21 \%$ at the higher concentration of $100 \mu \mathrm{g} / \mathrm{mL}$ after $24 \mathrm{~h}$. It is possible that the toxic effect of high doses of Bacoside A may inhibit the enzymes associated with cell cycle. The significant arrest of cells at sub-G0 phase is indicative of apoptosis thus suggesting that Bacoside $\mathrm{A}$ act by cell cycle-specific mechanism inducing apoptosis in GBM cells.

Most anti-cancer drugs eliminate rapidly proliferating cancerous cells, by inducing apoptosis [28]. Apoptosis is characterized by disintegration of plasma membrane, enzymatic cleavage of the DNA into fragments, and formation of apoptotic bodies [29]. We investigated the induction of apoptosis in GBM cells upon treatment with Bacoside A. Annexin V-FITC/PI assay by flow cytometry revealed that Bacoside A induced early apoptosis, but not necrosis, in GBM cells. Consistent with the MTT assay, the Annexin V-FITC/PI staining and DNA fragmentation studies demonstrated significant growth inhibitory effect of Bacoside A on GBM cells. DNA fragmentation which is a hallmark property of apoptosis further confirmed apoptosis in GBM cells. Furthermore, the morphology of the cells changed and the number of viable cells decreased under microscopic examinations.

Treatment of GBM cells with Bacoside A decreased notch1 expression and increased the levels of HES1 expression. $\mathrm{Nu}-$ merous studies have documented a direct correlation between high levels of notch1 expression and GBM pathogenesis $[8,30]$. Induced overexpression of HES1 in vitro and in vivo led to growth arrest and apoptosis in acute myeloid leukaemia and hepatocellular carcinoma supporting the tumour suppressor role of HES1 in these cancers [31-33]. Furthermore, gastric and prostate cancer cells with lower levels of notch 1 were prone to apoptosis and decreased cell proliferation $[34,35]$. Pretreatment of glioma cells with Notch1 siRNA prolonged survival in a murine orthotopic brain tumor model [8]. Furthermore, inhibition of Notch signaling through knockdown of notch receptors in GBM resulted in significant reduction in cell growth in vitro and in vivo [9]. Notch blockade in GBM derived neurosphere cultures by gamma secretase inhibitors reduced neurosphere growth and stem cell markers [36]. Additionally, there are studies showing increased expression of HES1 due to interference with notch1 expression inhibiting glioma cancer cells growth by inducing cell autophagy [37] and overexpression of HES1 inhibiting Notch1 signaling which in turn decreased tumor-initiating subpopulation in breast cancer [38]. Thus, these studies evidently display the oncogenic property of notch1 gene and tumor suppressor role of HES1 gene. Therefore, we report here that Bacoside A induced apoptosis in GBM cells in vitro may be dependent on Notch signaling pathway. The decreased levels of notch 1 and increased levels of HES1 may, in part, account for the high susceptibility of GBM cells to cell cycle arrest and apoptosis in response to Bacoside A.

Taken together, alterations in the expression of few Notch genes, DNA fragmentation, cell cycle arrest and apoptosis indicate that, Bacoside A may induce cell death in GBM. Both the levels of Notch genes and morphological changes in GBM cells after treatment with Bacoside A suggest a Notch-dependent cytotoxicity. This is also proved by the flow cytometric analysis showing cell cycle arrest and early apoptosis. Thus, Bacoside A via a novel mechanism of regulating Notch gene expression may provide a promising lead for GBM therapy. These findings thus provide new insights into the possible molecular mechanism of the cytotoxic activity of Bacoside A on GBM cells.

However, there are few limitations that need to be reported which could help in shaping the future research agenda. The effects of Bacoside A on the basic components of cell cycle regulation including cyclin-dependent kinases and their regulators, and apoptosis including caspases should be studied. To obtain the first mechanistic insights into the scenarios of Bacoside A induced cell death in vitro, a cell line that is well-established and most widely used in GBM studies was chosen. With these preliminary data, the efficacy of the compound should be subsequently extended to observe the effects on other GBM cell lines particularly IDH mutant and wild-type.

\section{Conflicts of Interest}

The authors have no potential conflicts of interest.

\section{Acknowledgments}

This study was funded by the Department of Biotechnology, New Delhi, India (grant number 6242-P20/RGCB/PMD/DBT/NRWR/2015). We thank Department of Neurovirology, NIMHANS, Bangalore, India, for the technical support. We thank Skanda Life Sciences, Bangalore, India for providing the flow cytometry and cell culture facility to carry out the work.

\section{REFERENCES}

1. Ostrom QT, Gittleman H, Liao P, et al. CBTRUS statistical report: primary brain and central nervous system tumors diagnosed in the United States in 2007-2011. Neuro Oncol 2014;16 Suppl 4:iv1-63.

2. Wen PY, Kesari S. Malignant gliomas in adults. N Engl J Med 2008;359: 492-507.

3. Imayoshi I, Sakamoto M, Yamaguchi M, Mori K, Kageyama R. Essential roles of Notch signaling in maintenance of neural stem cells in developing and adult brains. J Neurosci 2010;30:3489-98.

4. Axelson H. Notch signaling and cancer: emerging complexity. Semin Cancer Biol 2004;14:317-9.

5. Hansson EM, Lendahl U, Chapman G. Notch signaling in development and disease. Semin Cancer Biol 2004;14:320-8.

6. Dell'albani P, Rodolico M, Pellitteri R, et al. Differential patterns of NOTCH1-4 receptor expression are markers of glioma cell differentiation. Neuro Oncol 2014;16:204-16. 
7. Narayanappa R, Rout P, Aithal MG, Chand AK. Aberrant expression of Notch1, HES1, and DTX1 genes in glioblastoma formalin-fixed paraffin-embedded tissues. Tumour Biol 2016;37:6935-42.

8. Purow BW, Haque RM, Noel MW, et al. Expression of Notch-1 and its ligands, Delta-like-1 and Jagged-1, is critical for glioma cell survival and proliferation. Cancer Res 2005;65:2353-63.

9. Chen J, Kesari S, Rooney C, et al. Inhibition of notch signaling blocks growth of glioblastoma cell lines and tumor neurospheres. Genes Cancer 2010;1:822-35.

10. Hovinga KE, Shimizu F, Wang R, et al. Inhibition of notch signaling in glioblastoma targets cancer stem cells via an endothelial cell intermediate. Stem Cells 2010;28:1019-29.

11. Ridgway J, Zhang G, Wu Y, et al. Inhibition of Dll4 signalling inhibits tumour growth by deregulating angiogenesis. Nature 2006;444:1083-7.

12. Anbarasi K, Vani G, Balakrishna K, Devi CS. Effect of bacoside A on brain antioxidant status in cigarette smoke exposed rats. Life Sci 2006; 78:1378-84.

13. Simpson T, Pase M, Stough C. Bacopa monnieri as an antioxidant therapy to reduce oxidative stress in the aging brain. Evid Based Complement Alternat Med 2015;2015:615384.

14. Jyoti A, Sharma D. Neuroprotective role of Bacopa monniera extract against aluminium-induced oxidative stress in the hippocampus of rat brain. Neurotoxicology 2006;27:451-7.

15. Kumar EP, Elshurafa AA, Elango K, Subburaju T, Suresh B. Cytotoxic and anti -tumour properties of ethanolic extract of bacopa monnieri (L) penn. Anc Sci Life 1998;17:228-34.

16. Peng L, Zhou Y, Kong de Y, Zhang WD. Antitumor activities of dammarane triterpene saponins from Bacopa monniera. Phytother Res 2010;24: 864-8.

17. Elangovan V, Govindasamy S, Ramamoorthy N, Balasubramanian K. In vitro studies on the anticancer activity of Bacopa monnieri. Fitoterapia 1995;66:211-5.

18. Kalyani MI, Lingaraju SM, Salimath BP. A pro-apoptotic $15-\mathrm{kDa}$ protein from Bacopa monnieri activates caspase- 3 and downregulates Bcl-2 gene expression in mouse mammary carcinoma cells. J Nat Med 2013; 67:123-36.

19. Janani P, Sivakumari K, Geetha A, Ravisankar B, Parthasarathy C. Chemopreventive effect of bacoside A on $\mathrm{N}$-nitrosodiethylamine-induced hepatocarcinogenesis in rats. J Cancer Res Clin Oncol 2010;136:75970.

20. Janani P, Sivakumari K, Geetha A, Yuvaraj S, Parthasarathy C. Bacoside A downregulates matrix metalloproteinases 2 and 9 in DEN-induced hepatocellular carcinoma. Cell Biochem Funct 2010;28:164-9.

21. Prakash NS, Sundaram R, Mitra SK. In vitro and in vivo anticancer activity of Bacoside A from whole plant of Bacopa monnieri (Linn). Am J Pharmacol Toxicol 2011;6:11-9.

22. Deepak M, Sangli GK, Arun PC, Amit A. Quantitative determination of the major saponin mixture bacoside A in Bacopa monnieri by HPLC.
Phytochem Anal 2005;16:24-9.

23. John S, Sivakumar KC, Mishra R. Bacoside A induces tumor cell death in human glioblastoma cell lines through catastrophic macropinocytosis. Front Mol Neurosci 2017;10:171.

24. Rauf K, Subhan F, Al-Othman AM, Khan I, Zarrelli A, Shah MR. Preclinical profile of bacopasides from Bacopa monnieri (BM) as an emerging class of therapeutics for management of chronic pains. Curr Med Chem 2013;20:1028-37.

25. Singh HK and Dhawan BN. Neuropsychopharmacological effects of the ayurvedic nootropic Bacopa monnieri Linn. Indian J Pharmacol 1997;29:S359-65.

26. Stewart ZA, Westfall MD, Pietenpol JA. Cell-cycle dysregulation and anticancer therapy. Trends Pharmacol Sci 2003;24:139-45.

27. Nunez R. DNA measurement and cell cycle analysis by flow cytometry. Curr Issues Mol Biol 2001;3:67-70.

28. Kaufmann SH, Earnshaw WC. Induction of apoptosis by cancer chemotherapy. Exp Cell Res 2000;256:42-9.

29. Cotter TG. Apoptosis and cancer: the genesis of a research field. Nat Rev Cancer 2009;9:501-7.

30. Zhang XP, Zheng G, Zou L, et al. Notch activation promotes cell proliferation and the formation of neural stem cell-like colonies in human glioma cells. Mol Cell Biochem 2008;307:101-8.

31. Kannan S, Sutphin RM, Hall MG, et al. Notch activation inhibits AML growth and survival: a potential therapeutic approach. J Exp Med 2013; 210:321-37.

32. Tian C, Yu Y, Jia Y, Zhu L, Zhang Y. HES1 activation suppresses proliferation of leukemia cells in acute myeloid leukemia. Ann Hematol 2015; 94:1477-83.

33. Viatour P, Ehmer U, Saddic LA, et al. Notch signaling inhibits hepatocellular carcinoma following inactivation of the RB pathway. J Exp Med 2011;208:1963-76

34. Wei G, Chang Y, Zheng J, et al. Notch1 silencing inhibits proliferation and invasion in SGC 7901 gastric cancer cells. Mol Med Rep 2014;9: $1153-8$.

35. Ye QF, Zhang YC, Peng XQ, Long Z, Ming YZ, He LY. Silencing Notch-1 induces apoptosis and increases the chemosensitivity of prostate cancer cells to docetaxel through Bcl-2 and Bax. Oncol Lett 2012;3:879-84.

36. Fan X, Khaki L, Zhu TS, et al. NOTCH pathway blockade depletes CD133-positive glioblastoma cells and inhibits growth of tumor neurospheres and xenografts. Stem Cells 2010;28:5-16.

37. Yao J, Zheng K, Li C, Liu H, Shan X. Interference of Notch1 inhibits the growth of glioma cancer cells by inducing cell autophagy and downregulation of Notch1-Hes-1 signaling pathway. Med Oncol 2015;32:610.

38. So JY, Wahler J, Das Gupta S, et al. HES1-mediated inhibition of Notch1 signaling by a Gemini vitamin D analog leads to decreased CD44(+)/ CD24(-/low) tumor-initiating subpopulation in basal-like breast cancer. J Steroid Biochem Mol Biol 2015;148:111-21. 